@CEDA/TU, 2017, US Library of Congress, Catalog Card No.: 79-915209, ISSN: 2091-0339

The Journal of Development and Administrative Studies (JODAS), Vol. 25(1-2), pp. 1-10

\title{
Climate Change Adaptation related Hindrances among Rice Farmers in Nepal: Farm Level Analysis
}

\author{
Ram Kumar Phuyal ${ }^{1}$, Niranjan Devkota ${ }^{2}$, and Durga Lal Shrestha ${ }^{3}$
}

\begin{abstract}
The objective of this study is to measure the hindrances of climate change adaptation among rural rice farmers in Nepal and its possible way forward. This study was done in seven districts, one district from each of seven provinces, where three from Terai region (i.e. Bara, Dang and Kailali) and four from Hilly region (i.e. Ilam, Sindhuli, Syangja and Surkhet) of Nepal. A structural questionnaire with both closed and open - ended questions were prepared and used to obtain required information from 773 rice farming households from the targeted study areas. Interviews were conducted for the crop year 2016 and for the main season rice cultivation in Nepal covering from June/July to October/November of each year (i.e., monsoonal cultivation of paddy). Results show that, factors such as inadequate operational capital, poor access to weather forecast and climate change information, inadequate awareness program on climate change from government and non-government agencies are the major barriers for over 90 percent of the farmers surveyed by this study. Similarly, about 80 percent of the sample surveyed farmers opined that high cost of improving seeds, fertilizers and irrigation, inadequate knowledge on coping mechanism or in building resilience and inadequate access to credit facilities are the major hindrances to them for addressing weather and Climate Change (CC) related vagaries. Hence, the empirical results drawn from this study suggest that there is an urgent need in Nepal for greater investment at agrarian sector to address these farmers' level constraints and including supports for improving access to market and credit issues to farmers ( institutional and policy supports). Poor and ultra-poor farmers are more vulnerable from the vagaries of climate change, thereby immediate actions are needed from Ministry of Agriculture, and newly set up local government units in terms of more public investments at local and national level to enhance the climate change resilience of smallholding and poor farmers of Nepal.
\end{abstract}

Keywrords: Climate Change Adaptation, Barriers, Rural Rice Farmers, Way forward, Nepal.

\section{JEL Classification: Q10 \& Q54}

\section{Introduction}

Environmental factors acting as barriers or diverse of climate change adaptation are related to climate change impact, risk and vulnerability. Over the last decades, there have been a substantial increase in studies of the diverse and barriers that influence mitigation and adaptation efforts (Reckien, Flacke, Olazabal \& Heidrich, 2015). There are many definitions, synonyms and typologies of barriers that impede adaptations (Barnett et al., 2015). Barriers are factors, conditions or obstacles that decreased the effectiveness of adaptation strategies (Moser \& Ekstorm, 2010; Van, Byod \& Van, 2015). IPCC $5^{\text {th }}$ report characterized adaptation barriers as factors that make it harder to plan and implement adaptation actors that restrict options (Klein et al., 2014). Eisenack et al. (2014) argued that a barrier

\footnotetext{
${ }^{1}$ Dr. Phuyal is Associate Professor in Economics, Tribhuvan University Corresponding mail: phuyal ram5@yahoo.com

${ }^{2}$ Mr. Devkota is Ph.D. candidate of Economics, Tribhuvan University

${ }^{3}$ Dr. Shrestha is Professor in Economics, Tribhuvan University
} 
to adaptation is an impediment to specific adaptation for specific actors in their given context that arise from a condition or set of conditions. A barrier can be valued differently by different actors and can, in practice, be reduced overtime. In this definition, conditions are the attributes of adaptations, actors and their context (Eisenack et al., 2014). Focusing on barrier to adaptation is of popular importance as overcoming these challenges is often one of the primary targets of every adaptation efforts (Archie, 2014).

Barriers are defined as obstacles that can be overcome with concerned effort, creative management, change of thinking, prioritization and related shift in resources, land use and institutions (Moser \& Ekstorm, 2010). Nonetheless, barriers to adaptation are mostly social factors and conditions that hamper our ability to adapt proactively to future changes (Biesbroek, Klostermann, Termeer \& Kabat, 2013). A barrier is therefore a hindrance that can be overcome and is therefore not insurmountable; and such barriers are distinguished from limit, which are absolute and unsurpassable (Reckien et al., 2015). Further, institutional, socioeconomic and environmental factors are all important as barriers and diverse of climate plans (Reckien et al., 2015).

Identifying the specific barriers to adaptation for an organization can provide valuable information about where the adaptation process that organized currently resides (Archie, 2014). Identification of such barrier/ obstacles may be a promising approach to overcome them (Grüneis, Penker \& Höferl, 2016). Climate network are very effective support mechanism for both mitigation and adaptation planning, that predominantly large and economically prosperous cities engaged in mitigating and adaptation planning, and that particularly vulnerable cities in terms of future climate risk and anticipated impacts-have significantly fewer mitigation and adaptation plan today (Reckien et al., 2015). Although policy makers have little power to attain environmental factors such as climatic variables or location, an understanding how this factors are (or are not) related to engagement in climate planning is useful and necessary, for example, for the development of dedicated awareness campaigns and deciding whether to target financial and institutional support (Reckien et al., 2015).

Understanding of where, when and how barriers and limits to adaptation arise has become important frontier in climate change research (Barnett et al., 2015). Understanding of such barriers can allow more effective provisioning of resource and information to facilitate further progress in the adaptation process (Moser \& Ekstorm, 2010). Although, the concept of climate change adaptation has got so much attention from scholars all over the world, the limits and barriers in practice are still manifold (Grüneis et al., 2016). Limits and barriers to adaptation can be broadly categorized into three groups first, ecological and physical limit, second - human and information based limit and third - social barriers to adaptation (Jones \& Byod, 2011). Barnett et al. (2015) argued that the barriers to adaptation are context specific. Further, Eisenack et al. (2014) argued barriers are not static but changes over time. Barriers can be overcome with creative management, change thinking or concreated efforts (Van et al., 2015). Such barriers can be overcome with creative management, change thinking and concerned effort (Deressa, Hassan, Ringler, Alemu \& Yesuf, 2009). So far, there are only a few studies that explicitly investigate how barriers perceived as problematic might be overcome. A clear understanding of the underlying causes given rise to barrier would offer entry point for reducing of overcoming the barriers (Eisenack et al., 2014).

In agriculture, barriers of adaptation can be defined as factors, conditions, and obstacles that are believed to reduce the effectiveness of the farmers' adaptation strategies (Antwi-Agyei, Dougill \& Stringer, 2013; Van et al., 2015). Further, socio-economic factors, resource constrains and psychological factors have been widely identified as the major barriers to adaptation of farmers (Deressa et al., 2009; Nhemachena \& Hussain, 2007).They include poverty levels, societal hierarchies, lack of communication in case of threat, lack of information on adaptive measures, lack of access to credit, maladaptation, force to habit and the perception of the importance of climate change and adaptation (Van et al., 2015).

Many studies have focused on barriers to trigger to adaptation and these specifically identify policies and legal requirements (such as institutional frameworks, financial conditions, available technology, 
information, awareness and knowledge as well as external shocks) as factor which either motivate or restrain adaptation actors (Amundsen, Berglund \& Westskog, 2010). These factors are relevant at the local government level, as well as on other institutional scales, and are important in initiating adaptation to climate change. Thus, a large number of barriers and limit to adaptation have been identified, as well as facilitating factors. However, few studies have given an overview of adaptation measures undertaken across large number of local governments and barriers associated with implementing climate change (Amundsen et al., 2010).

Rice farmers in Nepal are adapting various adaptation options as to prevent their rice farmland. In their study, Devkota, Phuyal \& Shrestha (2017) identified that rural rice farmers have adopted 12 different adaptation options to prevent themselves from climatic anomalies. Several previous studies (Jones \& Byod, 2011; Regmi \& Bhandari, 2013) show that such adaptation is not easy to the rural level due to various diseconomies of scale. Such studies argued that rice production and its productivity in Nepal has been facing several constraints and challenges related to socio-economic and infrastructures that lead to low level of productivity (Joshi, 2017). It highlights that a large yield gap exists between what farmers are harvesting in their rice fields and what has been demonstrated by research. Therefore, the purpose of this paper is to measure the hindrances of climate change adaptation among rural rice farmers in Nepal and its possible way forward.

Despite many studies on climate change adaptation on agriculture (Devkota \& Phuyal, 2015), climate change adaptation on rice production (Devkota et al., 2017; Devkota \& Phuyal, 2017), little research is available on barrier to climate change adaptation by rice farmers. There is a need for research that focuses on the independencies between barriers and considers the dynamics ways in which barriers developed and persists, such research would help to explain barriers to adaptation and provide inside into how to overcome them (Eisenack et al., 2014). Therefore, this study aims to fulfill this research gap. This paper discusses the barriers encountered by rice farmers in adapting to climate change in rural Nepal.

The remaining parts of this paper are organized into three sections. The next section represents the material and methods of the study. Then the result and discussion on key findings are presented, followed by authors' concluding remarks.

\section{The Methodology}

The field study was conducted in seven districts that ranged from the hilly to Terai belts of Nepal and excluded the mountain belt ${ }^{4}$. The rice production environments of Nepal can be classified into three regions, Terai (60-900 $\mathrm{m}$ above sea), hilly (1100-1500 $\mathrm{m}$ above sea) and mountain (greater than 1500 $\mathrm{m}$ above sea), which contain 75 percent, 23 percent and 2 percent of the total cultivated land area respectively (Adhikari, Devkota \& Phulyal, 2017). The Terai belt is considered the grain basket of Nepal and has fertile agricultural land (Devkota \& Phuyal, 2015). Three study districts come from the Terai Belt, and four come from the hilly belt. The reason behind choosing seven districts is that there is one district from each state.

Nepal has observed varying temperatures, with a $0.04^{\circ} \mathrm{C}$ increase per year in Terai and a $0.09^{\circ} \mathrm{C}$ increase per year in the Himalayas, where there is a higher rate of increase in winter (Devkota \& Phuyal, 2015). The recorded rates of warming in the Himalayas are significantly higher than the global average since temperature in Nepal has increased by $1.8{ }^{\circ} \mathrm{C}$ during last 32 years (Shrestha, Wake, Mayewski \& Dibb, 1999; Adhikari et al., 2017). The distribution of rainfall has a wide range and is mostly linked with monsoon winds blowing from the Bay of Bengal. Nepal receives $80 \%$ of its rainfall during the monsoon season (Shrestha, et al., 1999; Pokharel\& Hallett, 2015). The main season for rice receives monsoon rain. Terai districts normally fall in irrigated rice fields, while hilly districts cover both irrigated and rain-fed rice fields due to topographical variations (Adhikari et al., 2017).

\footnotetext{
${ }^{4}$ This is because rice cultivation practices on the mountain belt are very rare and typically different that in the study area. Similarly, the rice cultivation period, cultivation techniques and adoption of adaptation differ from the remaining two belts.
} 
Abid, Scheffran, Schneider \& Ashfaq (2015) remarked that average household characteristics play an important role in shaping the decision-making process for climate change adaptation.

The study area selection was made based on rice pocket areas from different ecological zones in Nepal. As Abid et al. (2015) mentioned in their study, such a study area selection was made based on rice cropping regardless of cropping patterns, irrigation networks and climate prone zones. To select the study sites, this study used multi-sampling techniques. In the first stage, the seven districts of Nepal (one each from each state) were randomly selected for the overall study area. Telephone inquiries were made to each district agricultural office in order to collect rice pocket areas, which were mostly rice cultivated areas, within the district. In the second stage, $14 \mathrm{VDC}^{5}$ s (two from each district) were selected as the rice pocket area. Further telephone inquiries were made to each VDC secretary and social mobilizer in order to cross-check the given information from each district agricultural office. In the third stage, 28 rice pocket wards (two wards from each VDC), based on the information provided by the VDC secretary and social mobilizer, were selected. In the fourth stage, 28 farmers were selected from each ward on a convenience ${ }^{6}$ basis. During our field visit, we found that the information provided was correct, and the selected VDCs were the best rice pocket VDCs ${ }^{7}$ in the district. We excluded urban cities and VDCs under the assumption that cities and urban VDCs may be influenced by market-based adaptations. Selecting VDCs, therefore, had the advantage of a lesser influence by this market driven adoption, which was the primary reason to select VDC as the study area.

The survey was conducted between January and February of 2017. For the data collection, a total of 773 farmers were interviewed, irrespective of gender, farm size or tenancy status, through a farm household survey. Interviews were conducted for the 2016 crop year since the main season rice cultivation in Nepal occurs from June/July to October/November of each year. A fully structured questionnaire was used to gather information on socioeconomic and other characteristics of adaptation. Prior to the study, a pre-testing of the questionnaire was performed to avoid missing any important information. The enumerators received field training on the study objectives and the farm household survey and descriptive statistics were performed for data analysis.

\section{Result and Discussion}

\subsection{Climate Change Adaptation and Adaptation Cost}

To cope with changing climate, farmers have been adapting with possible adaptation system worldwide including rice farming (Joshi, 2017; Kim, Elisha, Lawrence \& Moses, 2017). Several studies like the studies of Jones \& Boyd (2011), Regmi \& Bhandari (2013), Shrestha, Gyawali \& Bhattarai (2014), Abid et al (2015), Devkota et al. (2017) revealed that in South Asia farmers have been adopting several adaptation options to increase their production as well as to protect them from climatic variation and change. Further, Devkota et al. (2017)mentioned that rice farmers in rural Nepal have been practiced 12 adaptation options. The 12 adaptation options are change in rice varieties (such as heat, flood, drought tolerance rice grains), denser plantation of local seeds, selecting short duration rice crops, starting/ increase in use of vitamins, increasing use of chemical fertilizers, pesticides and insecticides, changing size of land under cultivation, off farm activities (like diversifying from farming to non-farming activities), change in nursery date, change in planting date, build water harvesting schemes and change in irrigation practices (that includes alternative irrigations like boring, using motor for river water lifting). Among these adaptation options, farmers opined that increase use of chemical fertilizer, use of climate smart varieties and change in nursery date is common and most used adaptation options by them.

\footnotetext{
${ }^{5}$ VDC stands for Village Development Committee

${ }^{6}$ This study encountered difficulties in selecting farmers on the first day, since most farmers are not available in their houses when the enumerator was present in the area, which effected the selection procedure during sampling due to the availability of farmers in their home at the time of data collection. However, precautions were taken in regard to the distance to each household for the questionnaires. After every HH questionnaire was filled, few surrounding houses were left in regard to coverage of the entire study area.

${ }^{7}$ In each selected ward, rice farm households contained more than $90 \%$ of respondents.
} 
In their study Devkota et al. (2017) measured cost and benefit of adoption of climate change adaptation options among rural rice farmers in Nepal. Their result argued that among the adaptation options, farmers opined change in irrigation practice, denser plantation of seeds and using climate smart varieties are the first three costly options to adapt with their average adaptation cost USD ${ }^{8} 79.1$, USD 21.3 and USD 18.6 respectively. The overall cost per hectare is measured USD 941.66 which is more with farmers who adopt several adaptation options i.e. USD 942.60 in comparison to the farmers who does not adopt i.e. USD 938.50 per hectare. This result indicates that farmers who adopt bear more cost than those farmers who has not adapted yet. Such cost is lower in Terai region compared to Hilly region. Similar to cost, the overall per hectare revenue is USD 1296.00. Such revenue for the farmers who adapt and non-adapt is USD 1236.00 and USD 1455.00 respectively. It indicates nonadapter rice farmers in rural area able to get (received) high revenue compared to farmers who adopt adaptation options (Devkota et al., 2017).

\subsection{Hindrances to Adopt Available Adaptation Options among Rural Rice Farm}

Rice farmers were asked to ravel out the factors that hindering them to adopt available adaptation options. Factors such as inadequate capital, poor access to weather forecast and climate change information, inadequate awareness program on climate change from government and non-government agencies are the major barriers, as over 90 percent of the farmers reported so. Detailed results are summarized in Table 1. Similarly, 80 percent and above farmers opined that high cost of improving seeds, fertilizers and irrigation, inadequate knowledge on coping mechanism or built resilience and inadequate access to credit facilities are major among the given hindrances to the rice farmers.

Farmers argued that capital inadequacy is the first barrier as they are poor. Most of the other adaptations are also related to the price which comes again with the capital. They mentioned that high cost of fertilizer and no credit access are hindering their adaptation capacity along with the insufficient information and inadequate awareness. Further, there are several other barriers rice farmers are facing such as insufficiency of manpower, inadequate government policy and old farming technology and equipment.

Some study has undertaken major barrier to climate change on agriculture. Ndanami \& Watanabe (2015) argued that unpredictability of weather, high farm input cost, lack of access to timely weather information and lack of access to water resource are the most important barriers to farmers. Marshall, Gordon \& Ash (2011) observed that competing local priorities, lack of information and resources, institutional limitations and a culture or reacting management have been shown to pose a challenge for localized adaptation. Deressa et al. (2009)found shortage of farm labor is one of the major concern/ constrains to adaptation by farmers, further, most of the problems or constrains are associated with poverty. Amundsen et al. (2010) rightly remarked that budgetary constraints have been put forward as important consideration in the implementation of adaptive measures. Further, they observed unfamiliarity with and lack of data on climate change, lack of local expertise, lack of clear role for local governments when working with adaptation measures and policies. Nhemachena and Hassain (2007) found that lack of credit facilities, information on adaptation options and insufficient input are the major barrier to adapting any climate change adaptation options. Phuong, Biesbroek, Sen \& Wals (2017)has mentioned several barriers to implement adaptation strategies including market price fluctuations, lack of skilled labor, lack of climate change information and lack of capacity to learn and apply techniques in their daily practice. Further, poor irrigation system is important barrier to secure agricultural production; and lack of institutional capacity to facilitate agriculture adaptation to household level created an important barrier to further adaptation.

In country specific context of barriers to adaptation, Ozor et al. (2010) found that the major barriers to effective climate change adaptation in Southern Nigeria were land, poor climate change information, poor extension service delivery, huge cost of farm input, high cost of processing facilities, higher cost of irrigation facilities, credit constrains, labor constrains and income constrains. Similarly, Ifeanyi-Obi \& Issa (2013) observed eight major barriers faced by the Cassava farmers in Nigeria in adapting to climate change namely land and labor constrains, non-accessibility/ availability of farm input, non-

\footnotetext{
${ }^{8}$ USD (United States Dollar) 1 = NRs. 100
} 
availability/ high cost of farm facilities, farming practice and traditional belief, information constrains, poor agriculture service delivery, income constrains and government non-chalant attitude towards climate change issue. Besides, they observed other barriers like lack of information about climate change, lack of knowledge about adaptation options, lack of access to credit, no access to irrigation water and poor soil fertility. Kim et al. (2017 identified barriers to adaptation strategies in Nigerian rice production includes scarcity of improved varieties, insufficient credit facilities, poor economic status of farmers, inadequate extension services and poor information on climate change. In Nepal, caste along with ethnicity constitute the most important variables which have significant impact and implication for the individual capacity to adapt, particularly those among the lower class (Jones \& Byod, 2011).

Table 1: Causes or barriers that hinders farmers to adapt (in Number)

\begin{tabular}{|c|c|c|c|c|c|c|c|c|}
\hline & Ilam & Bara & Sindhuli & Syangja & Dang & Surkhet & Kailali & Total \\
\hline $\begin{array}{l}\text { Lack of/ or inadequate of capital/ } \\
\text { money/ saving }\end{array}$ & 96 & 92 & 85 & 80 & 98 & 101 & 80 & 632 \\
\hline $\begin{array}{l}\text { Lack of/ or inadequate access to } \\
\text { weather forecast information }\end{array}$ & 104 & 97 & 100 & 97 & 108 & 99 & 108 & 713 \\
\hline $\begin{array}{l}\text { Poor access to climate change } \\
\text { adaptation strategies information by } \\
\text { rice farmers }\end{array}$ & 105 & 99 & 97 & 101 & 109 & 100 & 107 & 718 \\
\hline $\begin{array}{l}\text { Lack of/ or inadequate awareness } \\
\text { and access to GO/ Development } \\
\text { partners/ NGOs program on climate } \\
\text { change adaptation }\end{array}$ & 101 & 97 & 95 & 102 & 106 & 91 & 110 & 702 \\
\hline $\begin{array}{l}\text { High cost of using improved rice } \\
\text { varieties }\end{array}$ & 62 & 99 & 83 & 100 & 108 & 68 & 90 & 610 \\
\hline $\begin{array}{l}\text { Inadequate knowledge on coping } \\
\text { mechanism or built resilience }\end{array}$ & 73 & 88 & 78 & 90 & 108 & 85 & 94 & 616 \\
\hline $\begin{array}{l}\text { High cost of fertilizer and other } \\
\text { inputs }\end{array}$ & 54 & 94 & 84 & 104 & 109 & 76 & 103 & 624 \\
\hline High cost of irrigation facilities & 27 & 60 & 37 & 10 & 51 & 20 & 57 & 662 \\
\hline Poor access to and control of land & 13 & 20 & 10 & 13 & 44 & 19 & 28 & 147 \\
\hline $\begin{array}{l}\text { Lack of/ or inadequate storage } \\
\text { facilities }\end{array}$ & 10 & 27 & 17 & 7 & 33 & 9 & 31 & 134 \\
\hline $\begin{array}{l}\text { Lack of/ or inadequate government } \\
\text { policies to empower rice growing } \\
\text { farmers }\end{array}$ & 66 & 75 & 65 & 71 & 80 & 70 & 84 & 511 \\
\hline $\begin{array}{l}\text { Lack of/ inadequate access to credit } \\
\text { facilities by various government or } \\
\text { I/NGOs }\end{array}$ & 88 & 96 & 83 & 94 & 99 & 87 & 100 & 647 \\
\hline Lack of Manpower & 89 & 77 & 79 & 71 & 59 & 47 & 47 & 469 \\
\hline $\begin{array}{l}\text { Lack of appropriate farming } \\
\text { technology and equipment }\end{array}$ & 94 & 85 & 82 & 83 & 90 & 81 & 71 & 586 \\
\hline Problem due to sloppy land & 38 & 3 & 17 & 26 & 3 & 6 & 3 & 96 \\
\hline Other (specify) & 3 & 6 & 1 & 8 & 12 & 3 & 17 & 50 \\
\hline
\end{tabular}

Source: Authors' Field Survey Data, 2017

Lack of credit facilities, agricultural subsidies, poor soil fertility are considered as moderate constrains whereas limited number of agricultural extension offices, agriculture market, limited farm size and farm labor are less important barriers (Ndamani \& Watanabe, 2015). The major adaptation barriers mentioned by rice farmers are socio-ecological factors, psychological factors and resource constrains, which are due to poverty level, lack of information and communication, and lack of adaptive measures, lack of access to credit, and the perception of the importance of climate change and adaptation (Deressa et al., 2009; Van et al., 2015). Lack of focus on adaptation at the national level has in turn led to a lack of attention to these issues at the local level (Amundsen et al., 2010). 


\subsection{Possible Way Forward on Climate Change Adaptation among Rural Rice Farmers}

To understand the farmers' opinion regarding the policy and strategic intervention for resilience to remove the existing hindrances, rice farmers were further asked to reveal the purpose to be done by policy makers and other relevant stakeholders to help them to adapt to the change.

\section{Figure 1: Farmer's opinion about strategic intervention for successful adaptation}

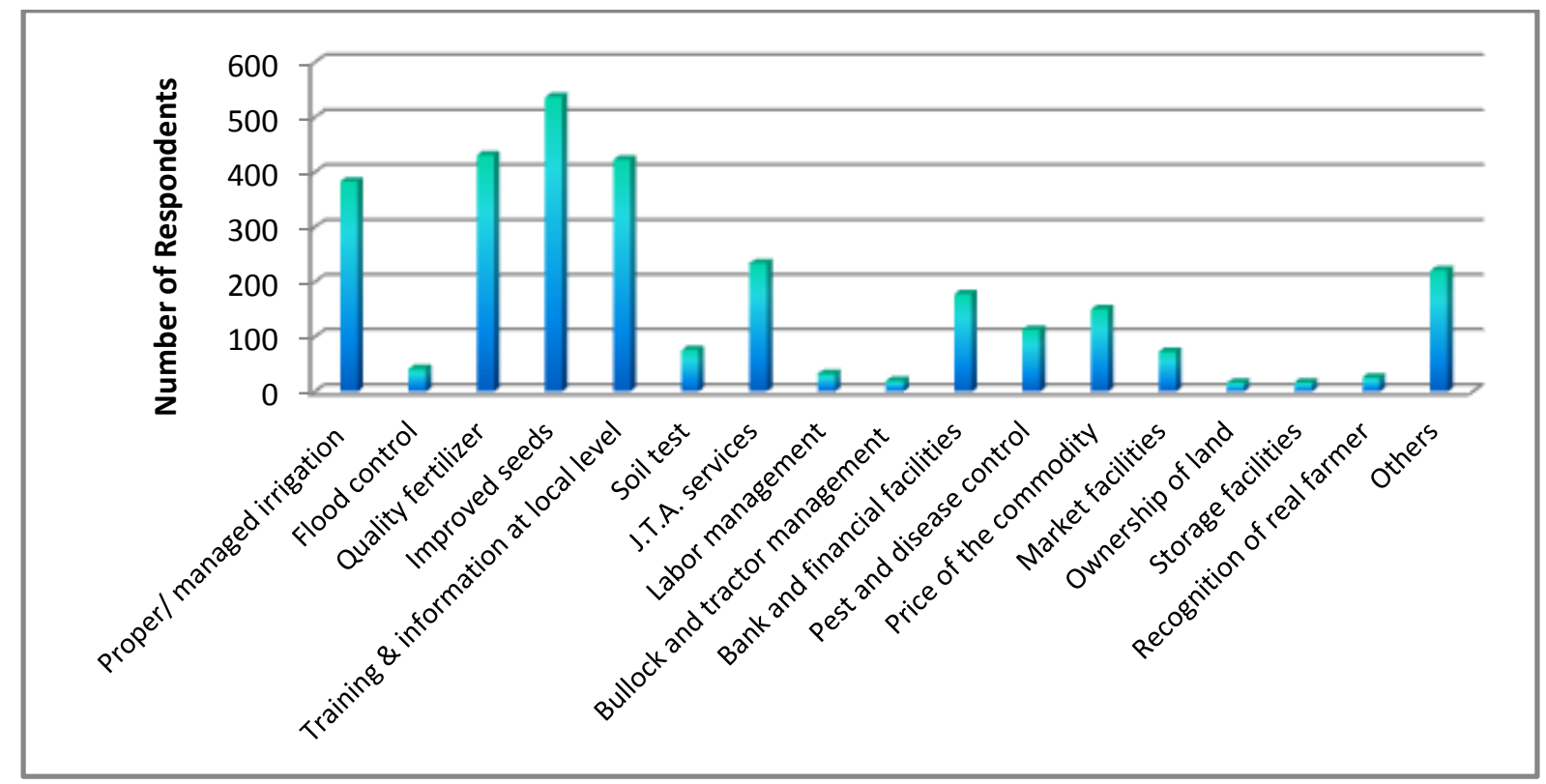

The result shows that for the removal of the hindrances rural rice farmers have to face adoption of climate change adaptation options and policy makers and other relevant stakeholders have to manage or help them to manage. Among the total respondents, $69.4 \%$ of rural rice farmers argued that timely improved seeds as per required quantity is most important policy and strategic intervention to adopt climate change adaptation options. Similar to improved seeds, $56 \%$ farmers opined quality fertilizer, $55 \%$ mentioned training and proper information at local level, help for the successful adaptation. Besides, $50 \%$ and $30 \%$ of farmers argued that managed irrigation and J.T.A. service respectively are responsible for better adaptation.

The surveyed farmers also mentioned that supports such as flood control, soil test, labor, bullock and tractor management, credit facilities through banking channel, pest and disease control, proper price of the paddy during sales, proper market facilities and easy access, ownership of land to the farmers who work, storage facilities help them to grow proper rice farming. Beyond all this, there are several other policy intervention farmers mentioned to require for the better farming under the verge of climate change. Such interventions are promotion of rural farmers' targeted program, proper road access, follow up the implemented policy and program, inflation control, reduction in middleman and corruption.

Policy and supportive environment guide stakeholders in planning and executing adaptation intervention as well as enable farming community to adapt to climate change (Ampaire et al., 2017). Government should mainstream barrier to, and choice of factors of adaptation practice to climate change related project and programs (Ndamani \& Watanabe, 2015). The government should also make more available of information on climate change and possible ways to overcome barriers to adaptation (Ifeanyi-Obi \& Issa, 2013).

The empirical results show need for multi-level governance framework in which the national government gives the clear right to municipalities through setting goals, creating regulations and financing adaptation process for the local governments to implement the necessary options and activities (Amundsen et al., 2010). Poor information on climate change is identified as an important barrier to adaptation strategies. Hence, government and other development actors 
should create useful meteorological centers in the rural areas to make accessible climate information to farmers via radio, television, and other mass communication means. This will also reinforce farmers' adaptability to climate change (Kim et al., 2017).

\section{Concluding Remarks}

This study reveals that farmers' adaptation strategies against vagaries of climate change differ with the adaptation options, and the knowledge they perceived regarding such adaptation options. However, focusing on cost of adaptation options is advantageous than other options. Investment in education, the supply of enough agricultural inputs, providing awareness about the use of chemical fertilizers and other adaptation options can be used as appropriate policy options to minimize the adverse effect of climate change on rural farmland in Nepal. This study indicates that there is need for greater investment to remove the barriers and institutional set up. Similarly, as the poor farmers are more vulnerable to changing climate which needs immediate actions that can be greater investment and subsidies for the counseling and prompt service, all of these factors would also help to improve poor rice farmers' wellbeing, as well.

This research can serve in policy making, for Ministry of Agriculture, Department of Agriculture, agriculture related organizations and regulatory bodies of Nepal. It remains asset in agencies working for climate change adaptation of Nepal by illuminating results presented adaptation made by the rice farmers in the rural area under hindrances. The exploitation of the study results can also be impetus in harmonizing climate related agriculture policy in Nepal. Therefore, a very sincere and sustained virtuous efforts and consortium of operations are required from the local, provincial and central governments to strengthen adaptation capacity of local farmers by removing hindrances depicted in the study.

\section{References}

Abid, M., Scheffran, J., Schneider, U. A., \& Ashfaq, M. (2015). Farmers' perceptions of and adaptation strategies to climate change and their determinants: The case of Punjab province, Pakistan. Earth System Dynamics, 6 (2015), 225-243.

Adhikari, V. R., Devkota, N. \& Phuyal, R. K. (2017). Impact of Climate Variation in Paddy Production in Nepal. Journal of Economic and Management Prospective. 11(3),1084-1092.

Ampaire, E. L., Jassogne, L., Providence, H., Acosta, M., Twyman, J., Winowiecki, L., \& van Asten, P. (2017). Institutional challenges to climate change adaptation: A case study on policy action gaps in Uganda. Environmental Science \& Policy, 75, 81-90.

Amundsen, H., Berglund, F., \& Westskog, H. (2010). Overcoming barriers to climate change adaptation: A question of multilevel governance? Environment and Planning C: Government and Policy, 28(2), 276-289.

Antwi-Agyei, P., Dougill, A. J., \& Stringer, L. C. (2013). Barriers to climate change adaptation in sub-Saharan Africa: Evidence from northeast Ghana and systematic literature review. (CCCEP Working Paper No. 154) \& (SRI Paper No. 52). London: Centre for Climate Change Economics and Policy and Sustainability Research Institute.

Archie, K. M. (2014). Mountain communities and climate change adaptation: Barriers to planning and hurdles to implementation in the Southern Rocky Mountain Region of North America. Mitigation and adaptation strategies for global change, 19(5), 569-587.

Barnett, J., Evans, L. S., Gross, C., Kiem, A. S., Kingsford, R. T., Palutikof, J. P., ... \& Smithers, S. G. (2015). From barriers to limits to climate change adaptation: path dependency and the speed of change. Ecology and Society, 20(3), 5.

Biesbroek, G. R., Klostermann, J. E., Termeer, C. J., \& Kabat, P. (2013). On the nature of barriers to climate change adaptation. Regional Environmental Change, 13(5), 1119-1129.

Deressa, T. D., Hassan, R. M., Ringler, C., Alemu, T., \& Yesuf, M. (2009). Determinants of farmers' choice of adaptation methods to climate change in the Nile basin of Ethiopia. Global Environmental Change, 19, 248-255.

Devkota, N., \& Phuyal, R. K. (2015). Climatic impact on wheat production in Terai of Nepal. Journal of Development and Administrative Studies, 23(1-2), 1-22. 
Devkota, N., \& Phuyal, R. K. (2017). An analysis of Nepalese youth understanding level on climate change. Asian Journal of Economic Modelling, 5(3), 342-353.

Devkota, N., Phuyal, R. K., \& Shrestha, D. L. (2017). Cost and benefit analysis of adoption of climate change adaptation options among rural rice farmers in Nepal. Asian Journal of Agriculture and Rural Development, 7(7), 136.

Eisenack, K., Moser, S. C., Hoffmann, E., Klein, R. J., Oberlack, C., Pechan, A., ... \& Termeer, C. J. (2014). Explaining and overcoming barriers to climate change adaptation. Nature Climate Change, 4(10), 867-872.

Grüneis, H., Penker, M., \& Höferl, K. M. (2016). The full spectrum of climate change adaptation: Testing an analytical framework in Tyrolean mountain agriculture (Austria). Springerplus, 5(1), 1848, 1-13.

Ifeanyi-Obi, C. C., \& Issa, F. O. (2013). Barriers faced by cassava farmers in adapting to climate change in Oron agricultural zone of Akwa Ibom State. IORS Journal of Agriculture and Veterinary Science, 4(6), 19-26.

Jones, L., \& Boyd, E. (2011). Exploring social barriers to adaptation: Insights from western Nepal. Global Environmental Change, 21, 1262-1274.

Joshi, G. R. (2017). Challenges and opportunities for enhancing rice production in Nepal. In M. N. Paudel, D. R. Bhandari, M. P. Khanal, B. K. Joshi, P. Acharya and K. S. Ghimire (Eds.), Rice Science and Technology in Nepal (pp. 719-736). Lalitpur: Crop Development Directorate. Retrieved from http://cddnepal.gov.np/downloadfile/Rice science and technology 1512106674.pdf

Kim, I., Elisha, I., Lawrence, E., \& Moses, M. (2017). Farmers adaptation strategies to the effect of climate variation on rice production: Insight from Benue state, Nigeria. Environment and Ecology Research, 5(4), 289-301.

Klein, R. J., Huq, S., Denton, F., Downing, T. E., Richels, R. G., Robinson, J. B., \& Toth, F. L. (2007). Inter-relationships between adaptation and mitigation. In: Parry, M.L., Canziani, O.F., Palutikof, J.P., van der Linden, P.J., Hanson, C.E. (eds) Inter-relationships between adaptation and mitigation. Climate change 2007: impacts, adaptation and vulnerability. Contribution of working group II to the fourth assessment report of the intergovernmental panel on climate change. Cambridge University Press, Cambridge, United Kingdom.

Marshall, N. A., Gordon, I. J., \& Ash, A. J. (2011). The reluctance of resource-users to adopt seasonal climate forecasts to enhance resilience to climate variability on the rangelands. Climatic Change, 107(3-4), 511-529.

Moser, S. C., \& Ekstrom, J. A. (2010). A framework to diagnose barriers to climate change adaptation. Proceedings of the national academy of sciences, 107(51), 22026-22031.

Ndamani, F., \& Watanabe, T. (2015). Determinants of farmers' adaptation to climate change: A micro level analysis in Ghana. Scientia Agricola, 73(3), 201-208.

Nhemachena, C., \& Hassan, R. (2007). Micro-level analysis of farmers adaption to climate change in Southern Africa. Intl Food Policy Res Inst.

Ozor, N., Madukwe, M. C., Enete, A. A., Amaechina, E. C., Onokala, P., Eboh, E. C., ......, \& Garforth, C. J. (2010). Barriers to climate change adaptation among farming households of southern Nigeria. Journal of Agricultural Extension, 14 (1), 114-124.

Phuong, L. T. H., Biesbroek, G. R., Sen, L. T. H., \& Wals, A. E. (2017). Understanding smallholder farmers' capacity to respond to climate change in a coastal community in Central Vietnam. Climate and Development, 1-16.

Pokharel, A. K., \& Hallett, J. (2015). Distribution of rainfall intensity during the summer monsoon season over Kathmandu, Nepal. Weather, 70(9), 257-261.

Reckien, D., Flacke, J., Olazabal, M., \& Heidrich, O. (2015). The influence of drivers and barriers on urban adaptation and mitigation plans: An empirical analysis of European cities. PloS one, 10(8), e0135597.

Regmi, B. R., \& Bhandari, D. (2013). Climate change adaptation in Nepal: Exploring ways to overcome the barriers. Journal of Forest and Livelihood, 11(1), 43-61.

Shrestha, A. B., Wake, C. P., Mayewski, P. A., \& Dibb, J. E. (1999). Maximum temperature trends in the Himalaya and its vicinity: An analysis based on temperature records from Nepal for the period 1971-94. Journal of Climate, 12(9), 2775-2786. 
Shrestha, S., Gyawali, B., \& Bhattarai, U. (2014). Impacts of climate change on irrigation water requirements for rice-wheat cultivation in Bagmati river basin, Nepal. Journal of Water and Climate Change, 4(4), 422-439.

Van, S. T., Byod, W., \& Van, M. T. (2015). Perception of climate change farmer's adaptation: A case study of poor and non-poor farmers in northern central coast of Vietnam. Journal of Basic and Applied Sciences, 11, 323-342.

Note: Views and opinions expressed in this article are the personal views of authors. 